\title{
KONTRIBUSI PENGGUNAAN MEDIA SOSIAL DALAM PERBANDINGAN SOSIAL PADA ANAK-ANAK AKHIR
}

\author{
CONTRIBUTION OF SOCIAL MEDIA USAGE \\ ON SOCIAL COMPARISON BEHAVIOR IN THE LATE CHILDHOOD PHASE
}

\author{
Oleh : \\ Siti Fauziah ${ }^{1}$ \\ Bani Bacan Hacantya ${ }^{2}$ \\ Anastasia Widya Paramita ${ }^{3}$ \\ Wiyanti Maratus Saliha ${ }^{4}$
}

\begin{abstract}
Submitted:

28 November 2019

Revision:

26 Mei 2020

Accepted:

10 Agustus 2020

Nowadays social media users are not limited to adults and teenagers, but are already used by children. Through social media they tend to do social comparisons. The purpose of this study is to examine the relationship between social media use and social comparison behavior in the late childhood phase. This study uses a correlational research design with a non random sampling technique. Participants studied were 101 subjects with the characteristics of grade VI elementary school students, could speak Indonesian, and have a social media account. Researchers took samples of one elementary school in Surabaya. The instrument used was a social comparison scale compiled by Gibbons \& Buunk (1999) based on social comparison theory according to Festinger (1945) and adapted by (Putra, 2017) and a list of social media usage activities by Rosen (2013). Based on the results of the study, it is known that the correlation coefficient obtained between the total score of social media use with the total social comparison score is 0.313 and significant at Los 0.01 ( $p$ value $=0.001<0.01$ ), which means there is a significant positive correlation between media use social to social comparison level. The higher the total score on the use of social media, the higher the level of social comparison scores, and vice versa. The role of parents is needed in the process of assisting late age children so as not to carry over the negative impacts of self-comparison through social media.
\end{abstract}

Keywords: Social media; social comparison; the late childhood phase

\begin{abstract}
ABSTRAK
Saat ini pengguna media sosial tidak terbatas pada dewasa dan remaja, tetapi sudah banyak digunakan oleh anak-anak. Melalui media sosial mereka cenderung melakukan perbandingan sosial. Tujuan dari penelitian ini untuk menguji hubungan antara penggunaan media sosial dan perilaku perbandingan sosial pada fase anak-anak akhir. Penelitian ini menggunakan desain penelitian korelasional dengan teknik pengambilan sampel non random sampling. Responden yang diteliti sebanyak 101 subyek dengan karakteristik siswa kelas VI SD, bisa berbahasa Indonesia, dan memiliki akun media sosial. Peneliti mengambil sampel satu Sekolah Dasar di Surabaya. Instrumen yang digunakan adalah skala perbandingan sosial yang disusun Gibbons \& Buunk (1999) berdasarkan teori perbandingan sosial menurut Festinger (1945) dan diadaptasi oleh (Putra, 2017) serta daftar aktivitas penggunaan media
\end{abstract}

\footnotetext{
${ }^{1}$ Siti Fauziah, Universitas Airlangga, Email : fauzziah@gmail.com

${ }^{2}$ Bani Bacan Hacantya, Universitas Airlangga, Email : hacantya@gmail.com

${ }^{3}$ Anastasia Widya Paramita, Universitas Airlangga, Email : paramita.anastasia@gmail.com

${ }^{4}$ Wiyanti Maratus Saliha, Universitas Airlangga, Email : maratuswiyanti@gmail.com
} 
sosial oleh Rosen (2013). Berdasarkan hasil penelitian, diketahui bahwa koefisien korelasi yang didapat antara skor total penggunaan media sosial dengan skor total perbandingan sosial adalah sebesar 0.313 dan signifikan pada Los 0,01 (nilai $\mathrm{p}=0,001<0.01$ ), yang berarti terdapat korelasi positif yang signifikan antara penggunaan media sosial dengan tingkat perbandingan sosial. Semakin tinggi skor total penggunaan media sosial maka skor tingkat perbandingan sosial akan semakin tinggi, begitu juga sebaliknya. Peran orang tua sangat dibutuhkan dalam proses pendampingan anak usia akhir agar tidak terbawa dampak negatif dalam perbandingan diri melalui media sosial.

Kata kunci: Media sosial; perbandingan sosial; fase anak-anak akhir

\section{PENDAHULUAN}

Seseorang mempunyai dorongan untuk membandingkan dirinya dengan orang lain. Proses tersebut dinamakan perbandingan sosial. Perbandingan sosial mempunyai fungsi sebagai pemenuhan kebutuhan afiliasi, mengevaluasi diri, membuat keputusan, regulasi emosi, dan kesejahteraan (Vogel, Roberts, \& Rose, 2014). Pentingnya perilaku perbandingan sosial karena merupakan bagian yang cukup vital dalam perkembangan identitas seseorang (Yang, Holden, Carter, \& Webb, 2018). Salah satu media yang digunakan seseorang untuk melakukan perbandingan sosial adalah media sosial (Doghlis, 2008). Media sosial menyediakan informasi tentang orang lain yang dapat digunakan untuk melakukan perbandingan sosial (Vogel, Rose,Okdie dan Eckles., 2015) dan menghubungkan banyak orang dalam dalam lingkungan sosial secara online melalui penggunaan website.

Saat ini seseorang cenderung berinteraksi menggunakan media sosial, sehingga penggunaan media sosial mengalami peningkatan. Banyak masyarakat di Indonesia yang aktif memakai media sosial seperti Instagram, Facebook, Snapchat, YouTube, ataupun Twitter sebagai wadah presentasi diri di dunia maya. Jumlah pengguna media sosial di Indonesia cukup banyak. Berdasarkan penelitian yang dilakukan oleh We Are Social bekerjasama dengan Hootsuite, dari 132,7 juta pengguna internet di Indonesia, 130 juta diantaranya adalah pengguna media sosial aktif. Data ini didukung dengan data hasil riset yang menunjukkan seberapa besar animo masyarakat Indonesia dalam memakai media sosial. Media-media sosial yang digandrungi oleh masyarakat Indonesia adalah You Tube 43\%, Facebook 41\%, Whatsapp 40\%, Instagram 38\%, Line 33\%, Blackberry Massanger 28\%, Twitter 27\%, Google+ 25\%, Facebook Messenger 24\%, LinkedIn 16\%, Skype 15\%, dan WeChat 14\% (Detik.com, 2018).

Penggunaan media sosial pada masa kini, tidak terbatas pada orang dewasa maupun remaja, namun juga sudah dilakukan oleh anak-anak akhir. Fakta yang cukup menarik ditunjukkan melalui survei 'Safer Internet Day' pada tahun 2016, saat ini ditemukan data bahwa $75 \%$ anak usia 10 sampai dengan 12 tahun telah memiliki akun media sosial, padahal batas usia minimal untuk membuat akun media sosial adalah 13 tahun (Metrotvnews, 2016). Pembatasan usia dalam pemakaian media sosial ini tentu berdasarkan pertimbangan tertentu. Salah satu alasan yang melandasi dibuatnya The Children's Online Privacy Protection Act (COPPA), perjanjian perlindungan privasi online anak yang diluluskan pada tahun 1998 didasarkan pada penelitian bahwa anak-anak membutuhkan sekitar satu tahun untuk sepenuhnya mengembangkan struktur kognitif yang memungkinkan mereka untuk terlibat dalam pemikiran etis, yang memahami dampak tindakan mereka terhadap orang lain, baik secara online, ataupun tidak. Terkadang anak-anak muda yang sudah bergabung dalam situs jejaring sosial dapat menjadi korban pelecehan online dan cyber-bullying sebelum mereka siap untuk menanggapi dengan tepat (Huffingtonpost, 2014). 
Penggunaan media sosial seperti Facebook, Instagram, YouTube maupun media sosial lainnya memungkinkan pengguna untuk menampilkan diri. Banyaknya animo masyarakat Indonesia yang memakai media sosial berarti memberikan banyak kesempatan terhadap adanya perilaku perbandingan sosial, karena media sosial menyediakan berbagai material untuk terjadinya perilaku tersebut (Yang \& Robinson, 2018). Pengguna dapat secara selektif mengikuti beberapa konten pada profil mereka, mengunggah foto, dan mendeskripsikan diri mereka sesuai dengan pandangan diri ideal mereka (Vogel,Roberts,Rose., 2014). Menurut Yang, Holden, Carter, Webb, (2018), menjelaskan bahwa media sosial menyediakan konten yang bagus untuk mempresentasikan diri secara positif. Hal tersebut secara tidak langsung menyebabkan seseorang melakukan perbandingan sosial atas (upward comparison), dalam hal ini individu membandingkan diri mereka dengan mereka yang tampak lebih baik. Penelitian Chou dan Edge (2012), dan Vogel, Roberts, Rose. (2014) menyebutkan bahwa para pengguna media sosial Facebook merasa bahwa pengguna lain lebih bahagia dan sukses daripada dirinya sendiri, terutama jika mereka tidak pernah bertemu secara offline.

Data menarik lain didapat melalui penelitian yang dilakukan oleh para peneliti di University of Sydney, Macquarie University dan UNSW Australia, yang menyatakan bahwa terlepas dari frekuensi waktu yang dihabiskan untuk menonton televisi, video musik dan penggunaan internet, wanita lebih sering membandingkan penampilan mereka dengan foto yang ada di majalah atau media sosial. Penelitian tersebut juga menyatakan bahwa media sosial bahkan seringkali dijadikan sebagai ajang perbandingan diri (Kompas.com, 2018). Oleh karena itu, dapat dikatakan bahwa kemudahan mengakses berbagai macam informasi melalui media sosial pada masa kini seringkali menjadi suatu tolak ukur perbandingan diri.

Sesungguhnya, perbandingan sosial terjadi secara "offline" karena melibatkan interaksi seseorang dengan kerabat-kerabat dekatnya, misalnya dengan rekan kerja, temanteman, dan keluarga. Bagi penggunanya, media sosial memberikan wadah untuk mencapai hal-hal penting di dunia offline, dalam versi online. Relevansi media sosial yang tinggi terhadap fungsi-fungsi sosial nyata inilah yang mengakibatkan orang-orang yang menggunakannya secara sadar ataupun tidak menjadikan media sosial sebagai fungsi perbandingan sosial (Haferkamp \& Kramer, 2011), sehingga pada akhirnya, seseorang mungkin akan membandingkan diri mereka yang realistis (offline) pada bentuk ideal yang ada di dalam dunia maya (online).

Perbandingan diri sebenarnya dapat memberikan manfaat yang baik ketika perbandingan tersebut dapat menginspirasi orang-orang untuk dapat menjadi seperti target perbandingan mereka (Lockwood \& Kumda, 1997; Vogel,Roberts,Rose.,2014). Sayangnya, hal ini juga berakibat merugikan pada well-being dan evaluasi diri (Vogel,Roberts,Rose., 2014). Perilaku ini sering menyebabkan orang-orang merasa tidak mampu, evaluasi diri rendah, dan mengalami afeksi negatif (Marsh \& Parker, 1984; Morse \& Gergen, 1970; Pzszczynski, Greenberg, \& LaPrelle, 1985). Hal ini juga didukung dengan adanya beberapa penelitian yang menunjukkan keterkaitan antara frekuensi tinggi penggunaan Facebook dengan perilaku depresi yang meningkat dan well-being yang berkurang (Feinstein, dkk., 2013; Kalpidou, Costin, \& Morris, 2011; Kross, dkk., 2013; Mehdizadeh, 2010; Rutledge, Gillmor, \& Gillen, 2013).

Menurut Festinger (1954) menyatakan bahwa seseorang memiliki kecenderungan untuk membandingkan diri mereka dengan orang lain dan memiliki dorongan untuk mengevaluasi kemampuan mereka melalui orang lain. Terdapat dua hal yang diperbandingkan yaitu pendapat (opinion) dan kemampuan (ability). Festinger (1954) mengajukan teori proses perbandingan sosial untuk menjelaskan perbandingan komparatif yang berhubungan dengan opini dan kemampuan seseorang. Festinger menyatakan bahwa individu termotivasi untuk membandingkan diri mereka sendiri dengan orang lain yang 
spesifik atau umum untuk menilai situasi sosial mereka sendiri. Individu cenderung untuk membandingkan diri mereka dengan individu lain yang serupa dengan dirinya sendiri, sebab dengan melakukan hal tersebut, maka evaluasi yang lebih tepat mengenai opini maupun kemampuan yang dimilikinya dapat tersedia.

Festinger (1954) menjelaskan bahwa perbandingan sosial mempunyai dua jenis yaitu: perbandingan sosial atas (upward social comparison) adalah membandingkan ciri atau kemampuan seseorang dengan orang lain yang lebih baik dari dirinya. Jenis yang kedua adalah perbandingan sosial bawah (downward social comparison) yang membandingkan ciri seseorang atau kemampuan seseorang dengan orang yang lebih buruk dari dirinya.

Motif atau tujuan perbandingan sosial menurut Festinger (1954) terdiri dari: (a) Evaluasi diri. Orang -orang tertarik khususnya pada perbandingan sosial untuk mengevaluasi diri mereka; (b) Perbaikan diri. Individu berjuang untuk melakukan perbaikan diri. Perbaikan diri digunakan untuk mempelajari bagaimana cara memperbaiki karakteristik tertentu dalam diri individu;(c) Peningkatan diri. Peningkatan diri muncul ketika individu ingin melindungi harga diri mereka dan mempertahankan pandangan positif tentang diri ketika mereka berada dalam ancaman atau ketidakpastian; (d)Pemahaman Komuni.

Orang juga sering membandingkan perasaan atau reaksinya dengan perasaan dan reaksi orang lain dalam situasi yang bisa menimbulkan perasaan senasib dan sepenanggungan. Kruglanski dan Mayseless (Kaplan dan Stiles, 2004) mendefinisikan perbandingan sosial sebagai penilaian komparatif mengenai stimulus sosial pada dimensi tertentu. Perbandingan ke atas dengan tujuan untuk pengembangan diri cenderung dilakukan oleh individu dengan self-esteem yang tinggi, namun perbandingan ini dapat memiliki efek negatif seperti frustasi, kecemburuan, kekerasan dan munculnya perasaan rendah diri. Hal tersebut akan muncul ketika individu merasa bahwa mereka kurang mampu mengendalikan peningkatan posisi mereka (Festinger, 1954; Kaplan \& Stiles, 2004).

Salah satu fenomena relevansi ini tampak pada istilah 'Facebook Envy' semakin banyak terjadi sejak media sosial semakin populer (Krasnova, Wenninger, Widjaja, \& Buxmann, 2013). Menurut penelitian ini, sikap cemburu ditunjukkan dengan perasaan frustasi setelah masuk ke dalam media sosial dan dibanjiri dengan notifikasi dari temanteman yang menunjukkan kebahagiaan sempurna dan hidup yang tak bercela di timeline mereka. Pembentukan rasa cemburu yang terjadi saat menganggap orang lain superior dibandingkan diri sendiri adalah suatu dimensi dalam perbandingan sosial (Smith \& Kim, 2007).

Efendi (1986) menyatakan, media sosial adalah komponen dari komunikasi interpersonal yang merupakan saluran atau sarana yang memfasilitasi pihak yang saling berkomunikasi secara tidak langsung. Media sosial adalah komunikasi yang menggunakan media internet. Internet muncul dikarenakan pesatnya perkembangan teknologi. Media sosial adalah suatu wadah untuk menghubungkan banyak orang dalam dalam lingkungan sosial secara online melalui penggunaan website (Doghlis, 2008). Media sosial memungkinkan pengguna untuk mengkonstruksi atau membuat profil secara elektronik dimana terdapat detail tentang hidup dan pengalaman, foto, hubungan pertemanan, rencana kegiatan sosial, bertemu dengan orang baru, melihat kehidupan orang lain, sebagai pemenuhan rasa memiliki, mengekspresikan kepercayaan pengguna, preferensi dan emosi pengguna (Vogel,Roberts,Rose., 2014).

Jalonen (2014) menjelaskan bahwa media sosial memiliki beberapa fungsi utama yaitu : media komunikasi, media kolaborasi, media penghubung, media pelengkap, dan media penggabung. Kekhasan perbandingan sosial online terletak pada pola perilaku membandingkan kompetensi, popularitas, keterhubungan sosial, dan kemampuan sosial, atau bahkan menilai apakah seseorang mencapai sesuatu yang lebih baik atau buruk dengan orang 
lain (Feinsten, dkk., 2013; Vogel,Roberts,Rose., 2014; de Vries \& Kühne, 2015 dalam Stapleton, Luiz, \& Chatwin, 2017). Penelitian-penelitian tersebut sebagian besar mengungkapkan beberapa implikasi negatif perilaku perbandingan sosial dalam bentuk 'menghakimi', seperti pandangan diri negatif, emosi negatif, dan gejala-gejala depresi (de Vries \& Kühne, 2015; Feinstein, dkk., 2013; Lim \& Yang, 2015; Vogel,Roberts,Rose., 2014; Weinstein, 2017). Perbandingan sosial berdasarkan bentuk 'menghakimi' (judgemental) menunjukkan perilaku membandingkan yang dilakukan dengan cara menganggap orang lain sebagai kompetitornya (Park \& Back, 2018) dan menilai apakah pencapaian kinerja mereka sendiri lebih tinggi atau lebih rendah dibandingkan yang lain (Festinger, 1954 dalam Gibbons \& Buunk, 1999). Dikhawatirkan ketika evaluasi diri rendah dan disertai oleh emosi negatif lainnya seperti perasaan tidak bahagia dan menderita, akan mengakibatkan timbulnya perasaan depresi bagi orang dengan perbandingan sosial ke atas (upward social comparison) yang tinggi.

Anak-anak masa akhir yang aktif menggunakan media sosial untuk berinteraksi sosial maupun menampilkan dirinya mempunyai kecenderungan untuk membandingkan dirinya dengan teman sebayanya sesama pengguna media sosial. Hal ini didukung oleh Santrock (2011) yang menyatakan bahwa anak-anak masa akhir memperoleh pemahaman diri mereka dengan cenderung menggunakan perbandingan sosial. Anak-anak akhir cenderung lebih suka menggunakan perbandingan untuk membedakan dirinya dengan orang lain. Mereka berfikir apa yang dapat dilakukannya dibandingkan dengan yang apa dapat dilakukan oleh anak lain. Masa anak-anak akhir sering disebut sebagai masa sekolah atau masa sekolah dasar. Masa anak-anak akhir berjalan dari usia 7 tahun sampai masuk ke masa pra remaja yang berkisar pada usia 11-13 tahun (Santrock, 2011).

Pada masa anak-anak akhir, anak-anak semakin mendeskripsikan diri mereka dengan karakteristik psikologis dan sifat-sifat yang berlawanan dengan deskripsi diri anak-anak kecil yang konkret. Anak-anak cenderung lebih mengenali aspek sosial dari dirinya. Mereka menggunakan referensi kelompok sosial dalam mendeskripsikan dirinya (Santrock, 2011). Pemahaman diri anak-anak juga ditandai dengan meningkatnya kecenderungan untuk melakukan perbandingan sosial. Anak-anak cenderung lebih suka menggunakan perbandingan untuk membedakan dirinya dengan orang lain. Mereka cenderung berfikir apa yang dapat dilakukannya dibandingkan dengan yang dapat dilakukan oleh anak lain (Santrock, 2011). Masa kanak-kanak (late chilhood) berlangsung dari usia 6 tahun sampai tiba saatnya individu menjadi matang secara seksual. Pada awal dan akhirnya, akhir masa kanak-kanak ditandai oleh kondisi yang sangat mempengaruhi penyesuaian pribadi dan penyesuaian sosial anak (Hurlock, 1980).

Melalui berbagai penelitian yang sudah dilakukan sebelumnya, banyak riset yang menunjukkan adanya hubungan media sosial dengan perbandingan sosial di kalangan usia remaja sampai dengan dewasa, sedangkan penelitian di kalangan usia anak-anak masih belum banyak dieksplorasi, padahal pengguna media sosial anak-anak di bawah usia 13 tahun sudah semakin bertambah banyak. Kebutuhan akan data penelitian hubungan media sosial terhadap perilaku perbandingan sosial di usia anak-anak akan sangat krusial bagi perkembangan peta psikologis sosial emosional anak Indonesia, sehingga penelitian ini sangat penting untuk dilakukan.

Melihat dari latar belakang masalah tersebut, penelitian ini penting dilakukan untuk mengetahui apakah ada signifikansi hubungan antara penggunaan media sosial dan perilaku perbandingan sosial pada anak-anak akhir. Hipotesis dalam penelitian ini adalah (Ho) tidak terdapat hubungan antara penggunaan media sosial dan perbandingan sosial pada masa anakanak akhir, dan (Ha) terdapat hubungan antara penggunaan media sosial dan perbandingan sosial pada masa anak-anak akhir. Tujuan dari penelitian ini untuk mengetahui pengaruh 
media sosial terhadap perbandingan sosial Terdapat hubungan antara penggunaan media sosial dan perbandingan sosial akhir.

\section{METODE PENELITIAN \\ Responden Penelitian}

Pada penelitian ini populasi yang diteliti adalah siswa kelas 6 SD yang termasuk pada tahap perkembangan anak-anak akhir. Peneliti menggunakan sampel sebanyak 101 responden yang terdiri dari siswa dan siswi kelas 6 SD. Karakteristik responden yang diteliti adalah bisa berbahasa Indonesia, dapat membaca dan menulis, dan memiliki akun media sosial.

Teknik pengambilan sampel yang digunakan dalam penelitian ini adalah non random sampling. Teknik ini adalah salah satu metode sampling yang digunakan ketika jumlah individu yang berada dalam populasi tidak dapat diketahui (Kumar, 2005). Salah satu metode dalam non random sampling adalah accidental sampling (Graveter \& Forzano, 2009). Pada teknik ini, peneliti menggunakan responden yang mudah ditemui. Responden dipilih berdasarkan kesediaan dan keinginan untuk berpartisipasi dalam penelitian ini. Penelitian ini menggunakan institutional based, yaitu school based. Peneliti mengirim surat ke institusi tujuan untuk diajak bekerjasama dalam pengambilan data pada periode yang telah peneliti tentukan. Peneliti mengambil sampel di satu Sekolah Dasar di Kota Surabaya.

\section{Tipe dan Desain penelitian}

Prosedur penelitian ini adalah penelitian kuantitatif dengan menggunakan survei, yaitu mengukur banyak subjek dengan pertanyaan yang sama untuk mengukur variabel tertentu (Neuman, 2003). Kumar (2005) menyatakan, berdasarkan tipe informasi yang diambil, penelitian ini termasuk penelitian kuantitatif. Penelitian kuantitatif merupakan suatu penelitian yang mengukur variasi fenomena yang berupa variabel-variabel, variabel ini akan menghasilkan skor. Kesimpulan dan interpretasi dari skor yang diperoleh kemudian disampaikan dalam bentuk analisis statistik (Kumar, 2005). Berdasarkan tujuan penelitian, penelitian ini termasuk correlational research atau penelitian korelasional. Penelitian korelasional berusaha untuk menemukan adanya hubungan di antara dua atau lebih variabel (Kumar, 2005).

\section{Prosedur Penelitian}

Pengambilan data dilakukan di sekolah dan responden akan mengisi di kelasnya masing-masing. Sebelum mengisi, peneliti memberikan penjelasan singkat mengenai penelitian dan prosedur pengisian kuesioner. Responden diharuskan mengisi dan menandatangani inform consent sebelum melengkapi kuesioner yang diberikan.

\section{Instrumen Pengukuran}

Alat yang digunakan peneliti dalam pengumpulan data penelitian ini adalah kuesioner. Kuesioner merupakan salah satu bentuk pengukuran self report (Graveter \& Forzano, 2009). Kuesioner terdiri dari inform consent, data kontrol, kuesioner penggunaan media sosial, dan skala perbandingan sosial.

Kuesioner Penggunaan Media Sosial: skor pada kuesioner penggunaan media sosial didasarkan pada frekuensi melakukan kegiatan di media sosial. Daftar aktivitas penggunaan media sosial berdasar pada penelitian Rosen, 2013 mengenai skala penggunaan dan sikap terhadap media sosial dan teknologi. Peneliti menggunakan sub skala penggunaan media sosial yang terdiri dari delapan pernyataan. Skoring yang dilakukan adalah dengan mengkoding skor responden tidak pernah (1), sekali dalam sebulan (2), beberapa kali dalam sebulan (3), sekali dalam seminggu (4), beberapa kali dalam seminggu (5), sekali dalam 
sehari (6), beberapa kali dalam sehari (7), per jam (8), beberapa kali dalam satu jam (9), dan setiap saat (10).

Peneliti tidak melakukan uji reliabilitas dan validitas terhadap sub-skala penggunaan media sosial. Namun pembuat skala ini, yaitu Rosen, K. Whaling, Carrier, \& Rokkum (2013) telah melakukan uji validitas untuk melihat kesahihan sub-skala ini tepat dalam mengukur penggunaan media sosial dan dipaparkan pula reliabilitas dari sub-skala penggunaan media sosial. Berdasarkan pengujian yang dilakukan oleh pembuat alat ukur, diperoleh reliabilitas alat ukur yang dilihat berdasarkan koefisien alfa nya. Koefisien alfa pada masing-masing sub-skala dihitung, dan diperoleh nilai 0.96 untuk sub-skala penggunaan media sosial. Bukti untuk validitas diukur dengan menghubungkan skala dengan beberapa skala dan kuesioner lain yang terkait, yaitu kuesioner berapa jam lama penggunaan media dalam sehari, skala kecemasan dalam penggunaan teknologi, dan skala adiksi internet dari Youngs (1998) dalam Rosen, dkk (2013).

Skala Perilaku Perbandingan Sosial: Skala perbandingan sosial yang digunakan adalah skala yang disusun Gibbons \& Buunk (1999) berdasarkan teori perbandingan sosial menurut Festinger (1945) dan diadaptasi oleh Putra (2017). Skala ini memiliki dua dimensi, yaitu dimensi kemampuan (ability) dan pendapat (opinion). skala perbandingan sosial memiliki 11 item. Item berupa pernyataan, jawaban subjek diukur dengan skala likert skala 14, 1 berarti sangat tidak sesuai, 2 tidak sesuai, 3 sesuai, dan 4 sangat sesuai. Jawaban di skala ini dimodifikasi menjadi 4 skala dan menghilangkan kategori tengah atau netral. Menurut Hadi (1991), modifikasi yang dilakukan pada skala Likert bertujuan untuk mengurangi kelemahan skala likert lima tingkat. Modifikasi skala Likert menghilangkan kategori jawaban netral yang berada di tengah karena kategori netral memiliki arti ganda. Menurut konsep asli skala Likert, jawaban kategori yang berada di tengah berarti belum bisa memutuskan atau memberi jawaban, bisa juga diartikan netral (buka setuju maupun tidak setuju) atau bahkan ragu-ragu. Selain itu, jawaban yang berada di tengah menimbulkan kecenderungan responden untuk menjawab di bagian tersebut (central tendency effect).

Peneliti tidak melakukan uji reliabilitas dan validitas terhadap skala perbandingan sosial. Namun pembuat alat ukur ini, yaitu Gibbons \& Buunk (1999) dan Putra (2017) yang melakukan adaptasi telah melakukan uji validitas untuk melihat sejauh mana skala ini tepat dalam mengukur perbandingan sosial dan dipaparkan pula reliabilitas dari skala.Berdasarkan pengujian yang dilakukan oleh Gibbons \& Buunk (1999), diperoleh reliabilitas skala yang dilihat berdasarkan koefisien alfa-nya, yaitu 0.81,sedangkan adaptasi dari Putra (2017) menunjukkan koefisien alfa 0.824 .

Validitas skala ini diuji dengan berbagai metode (Gibbons \& Buunk, 1999), diantaranya validitas konstruk dengan teknik validasi known-groups, yaitu membandingkan responden dari dua negara yang berbeda. Selain itu dilakukan pengujian korelasi antara trait yang berkaitan dengan variabel perbandingan sosial berdasarkan teori Festinger.

\section{Teknis Analisis Data}

Pengolahan data dilakukan dengan menggunakan aplikasi SPSS versi 20. Peneliti menggunakan teknik statistik deskriptif: perhitungan ini digunakan untuk mendapatkan gambaran umum mengenai karakteristik dari sampel penelitian, seperti mean dan frekuensi. Teknik selanjutnya adalah Pearson Correlation: perhitungan ini digunakan untuk mengetahui kekuatan dan arah hubungan antara dua variabel. Pearson correlation didesain untuk variabel kontinyu (Pallant, 2011). Teknik ini digunakan untuk menghitung korelasi antara skor penggunaan media sosial dan skor perilaku perbandingan sosial. 


\section{HASIL DAN PEMBAHASAN}

Berikut ini hasil yang didapatkan dalam penelitian ini berdasarkan hasil isian kui dari subyek penelitian sebagaiamana tabel dibawah ini

Tabel 1.

Gambaran Karakteristik Responden

\begin{tabular}{llll}
\hline Data Kontrol & & N & Persentase \\
\hline Jenis kelamin & Laki-laki & 55 & $54.5 \%$ \\
& Perempuan & 46 & $45.5 \%$ \\
\hline Usia & 10 tahun & 2 & $1.98 \%$ \\
& 11 tahun & 74 & $73 \%$ \\
& 12 tahun & 25 & $24.8 \%$ \\
\hline Lama pemakaian & Kurang dari satu & 26 & $25.7 \%$ \\
& tahun & & 41 \\
media sosial & $1-2$ tahun & $44.6 \%$ \\
& Lebih dari 2 tahun & 34 & $33.7 \%$ \\
\hline
\end{tabular}

Tabel 1 gambaran karakteristik responden dapat dilihat jumlah responden dengan jenis kelamin laki-laki sebanyak 55 orang $(54.5 \%)$ dan perempuan 46 orang $(45.5 \%)$. Sedangkan usia responden memiliki rentang dari 10-12 tahun, responden yang berusia 10 tahun sebanyak 2 orang (1.98\%), responden berusia 11 tahun sebanyak 74 orang (73\%), dan responden berusia 12 tahun sebanyak 25 responden (24.8\%). Dari tabel terlihat bahwa lama pemakaian media sosial paling banyak adalah 1-2 tahun, yaitu sebanyak 41 orang (40.6\%), kemudian lebih dari 2 tahun sebanyak 34 orang (33.7\%), dan kurang dari satu tahun sebanyak 26 orang $(25.7 \%)$.

Tabel 2.

Jenis Media Sosial yang Digunakan

\begin{tabular}{llll}
\hline Media Sosial & $\mathbf{N}$ & Persentase & Persentase Kasus \\
\hline Instagram & 86 & $43.0 \%$ & $86.9 \%$ \\
Facebook & 14 & $7.0 \%$ & $14.1 \%$ \\
Twitter & 2 & $1.0 \%$ & $2.0 \%$ \\
Youtube & 86 & $43.0 \%$ & $86.9 \%$ \\
Musical.ly & 4 & $2.0 \%$ & $4.0 \%$ \\
Tiktok & 8 & $4.0 \%$ & $8.1 \%$ \\
\hline Jumlah & 200 & $100.0 \%$ & $202.0 \%$ \\
\hline
\end{tabular}

Tabel 2 menunjukkan bahwa data dari multiple response yang diberikan responden mengenai jenis media sosial yang digunakan menunjukkan bahwa Instagram dan Youtube merupakan media sosial yang paling banyak digunakan oleh responden, sebanyak 86 orang menjawab menggunakan Instagram dan Youtube $(86.9 \%$ responden menggunakan dua media sosial ini). Kemudian Facebook berada di urutan selanjutnya, yaitu sebanyak 14 orang (14.2\% responden menggunakan facebook). Lalu Tiktok, Musical.ly, dan Twitter secara berurutan 8,4 , dan 2 orang $(4 \%, 2 \%, 1 \%)$.

Tabel 3.

Aktivitas Media Sosial

Kegiatan Mean




\begin{tabular}{ll}
\hline Masuk dan melihat notifikasi akun media sosial & 5.1 \\
Masuk dan melihat notifikasi akun media sosial di sekolah & 1.7 \\
Posting status/story & 3.2 \\
Memposting foto/video & 3.4 \\
& 5.3 \\
Melihat profil atau akun orang lain & 4.7 \\
Membaca/scrolling time line media sosial & 5.3 \\
Menyukai (klik like) postingan/foto/video orang lain & \\
Komen postingan/foto/video orang lain & 3.1 \\
\hline
\end{tabular}

Tabel 3 menunjukkan intensitas aktivitas penggunaan media sosial yang dilakukan responden. Kegiatan yang paling sering dilakukan oleh responden adalah melihat profil atau akun orang lain (5.3), menyukai potingan/foto/video orang lain (5.3), dan masuk dan melihat notifikasi akun media sosial (5.1). Namun kegiatan masuk dan melihat notifikasi media sosial jarang dilakukan di sekolah, hal ini terlihat di mean yang paling kecil (1.7). Selanjutnya urutan intensitas aktivitas responden adalah membaca time line media sosial (4.7), mengunggah foto/video (3.4), mengunggah status/story (3.2), dan berkomentar di posting orang lain (3.1).

Sebelum dilakukan uji hipotesis dilakukan uji asumsi. Uji normalitas digunakan untuk mengetahui apakah populasi data mengikuti distribusi normal atau tidak. Hasil uji normalitas dalam penelitian ini adalah sebagai berikut:

Tabel 4.

Tes Normalitas Kolmogorov-Smirnov

\begin{tabular}{lll}
\hline & Sig. & Asumsi Normalitas \\
\hline Penggunaan Media Sosial & 0.05 & Terpenuhi \\
Tingkat Perbandingan Sosial & 0.48 & Terpenuhi \\
\hline
\end{tabular}

Tabel 4 menunjukkn hasil siginifikansi uji normalitas Kolmogorov-Smirnov dilakukan karena jumlah sampel lebih dari 50. Dua variabel menunjukkan hasil siginifikansi lebih dari 0.05 (Penggunaan Media Sosial sig 0.05, Tingkat Perbandingan Sosial sig. 0.48), sehingga data dari kedua variabel adalah data yang persebarannya normal.

Tabel 5.

Uji Linearitas

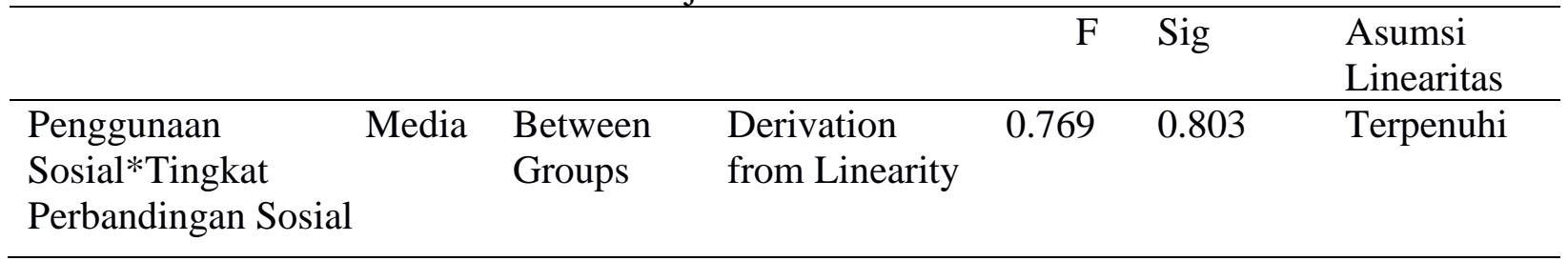

Tabel 5 menunujukkna uji asumsi yang kedua adalah linearitas, berdasarkan hasil uji linearitas pada tabel di atas, diketahui bahwa nilai signifikansi deviation from linearity= 0.803 , karena nilai sig $0.803>0.05$ berarti terdapat hubungan linier antara variabel penggunaan media sosial dengan variabel tingkat perbandingan sosial.Berdasarkan uji 
asumsi, diketahui bahwa data tersebut sudah memenuhi asumsi yang menjadi persyaratan yaitu uji normalitas dan uji liniearitas. Berikut hasil uji korelasi Pearson:

Tabel 6.

Uji Korelasi Pearson

\begin{tabular}{llll}
\hline Variabel & & $\begin{array}{l}\text { Penggunaan } \\
\text { Media Sosial }\end{array}$ & $\begin{array}{l}\text { Perbandingan } \\
\text { Sosial }\end{array}$ \\
\hline Penggunaan Media Sosial & Pearson correlation & 1 & $0.313^{* *}$ \\
\cline { 2 - 4 } & Sig. (2-tailed) & & 0.001 \\
\cline { 2 - 4 } & $\mathrm{N}$ & 101 & 101 \\
\hline Perbandingan Sosial & Pearson correlation & $0.313^{* *}$ & 1 \\
\cline { 2 - 4 } & Sig. (2-tailed) & 0.001 & 101 \\
\cline { 2 - 4 } & $\mathrm{N}$ & 101 & \\
\hline
\end{tabular}

**korelasi signifikan pada level 0,01 (2-way)

Tabel 6 diketahui bahwa koefisien korelasi yang didapat antara skor total perilaku kekerasan dengan skor total index autoritatif adalah sebesar 0.313 dan signifikan pada Los 0,01 (nilai $\mathrm{p}=0,001<0.01$ ). Ini berarti terdapat korelasi positif yang signifikan antara penggunaan media sosial dan tingkat perbandingan sosial. Artinya, semakin tinggi skor total penggunaan media sosial maka skor tingkat perbandingan sosial akan semakin tinggi, begitu juga sebaliknya. Jadi semakin tinggi penggunaan media sosial maka tingkat perbandingan sosial akan semakin tinggi dan sebaliknya.

Hasil penelitian menunjukkan bahwa terdapat hubungan positif antara penggunaan media sosial dan tingkat perbandingan sosial pada anak-anak akhir. Hal ini sejalan dengan penelitian Yang, Holden, Carter, \& Webb (2018) yang mengatakan bahwa banyaknya informasi yang dihasilkan oleh teman sebaya dapat menjadikan media sosial sebagai wadah untuk perbandingan sosial. Misalnya, dengan melihat media sosial milik temannya, seseorang akan dapat mengetahui seberapa baik mereka dalam menyesuaikan diri, tapi juga merasakan tekanan untuk menampilkan hanya sisi positif mereka, dimana hal ini memungkinkan terhambatnya ekspresi penuh dan eksplorasi diri yang penting dalam pembentukan identitas.

Karakteristik perkembangan psikososial anak-anak akhir adalah cenderung lebih mengenal aspek sosial dari dirinya. Kelompok sosial digunakan sebagai referensi untuk mendeskripsikan dirinya (Santrock, 2011). Peningkatan kecenderungan untuk melakukan perbandingan sosial dialami oleh anak-anak pada fase akhir perkembangan mereka menuju fase remaja awal, seiring dengan peningkatan pemahaman diri individu. Sementara itu, penggunaan media sosial mengalami peningkatan di kalangan anak-anak akhir. Saat ini, seseorang cenderung berinteraksi menggunakan media sosial. Dari hasil data kontrol responden dapat diketahui bahwa hampir sembilan puluh persen responden setidaknya menggunakan dua media sosial, yaitu Instagram dan Youtube. Aktivitas penggunaan media sosial yang paling banyak dilakukan oleh responden adalah melihat profil atau foto orang lain dan menyukai postingan orang lain.

Media sosial merupakan wadah yang dapat memfasilitasi perbandingan sosial karena konten yang ada di dalamnya (Yang, Holden, Carter, \& Webb, 2018).Penggunaan media sosial seperti facebook, instagram, youtube maupun media sosial lainnya memungkinkan pengguna untuk menampilkan diri. pengguna dapat secara selektif mengikuti beberapa konten pada profil mereka, memposting foto, dan mendeskripsikan diri mereka sesuai dengan pandangan diri ideal mereka (Vogel,Roberts,Rose., 2014) Perbandingan sosial dalam media 
sosial terjadi ketika pengguna menghubungkan tentang seberapa baik atau buruknya diri mereka dibandingkan dengan orang lain setelah melihat profil atau posting orang lain (Lee, 2014; Vogel,Roberts,Rose., 2014). Perbandingan sosial online tercermin pada perilaku membandingkan diri dengan kemampuan, popularitas, kemampuan sosial, dan jaringan sosial atau menilai apakah pencapaian seseorang lebih baik atau buruk dibandingkan orang lainnya (Feinsten dkk., 2013; Stapleton, Luiz, \& Chatwin, 2017; Vogel,Roberts,Rose., 2014; de Vries \& Kühne, 2015).

\section{KESIMPULAN}

Kesimpulan dari penelitian ini adalah terdapat korelasi positif yang signifikan antara penggunaan media sosial dan tingkat perbandingan sosial. Artinya, semakin tinggi skor total penggunaan media sosial maka skor tingkat perbandingan sosial akan semakin tinggi, begitu juga sebaliknya. Keterbatasan dalam penelitian ini terletak pada proses sampling, yaitu hanya melibatkan satu sekolah sehingga karakteristik sampel kurang beragam dan bisa jadi memiliki kebiasaan yang cukup serupa. Saran bagi pengembangan penelitian selanjutnya, dapat dilakukan pengukuran perbandingan sosial yang lebih spesifik agar dapat menjelaskan tipe perbandingan sosial yang dilakukan oleh sampel, sehingga data menjadi lebih kaya. Proses pengambilan sampel juga dapat melibatkan sekolah-sekolah dasar lain, seperti sekolah negeri agar sampel yang diperoleh lebih representatif. Peneliti menyarankan kepada orang tua untuk mengawal dan memberikan pendampingan pada anak saat menggunakan media sosial perlu dilakukan. a agar dapat mengantisipasi efek media sosial terhadap perkembangan anak. Bagi para pendidik agar dapat memberikan pengetahuan dasar literasi media sosial yang baik bagi para siswa, sehingga siswa dapat menggunakan media sosial secara baik dan benar.

\section{DAFTAR PUSTAKA}

Amalia, E.I. (2016, February 10). Anak di Bawah 13 Tahun Sudah Gunakan Media Sosial. Metrotvnews.com. Retrieved from http://teknologi.metrotvnews.com/. Diakses pada 05 Januari 2020

Chou, H. -T. G., \& Edge, N. (2012). "They are happier and having better lives than I am": The impact of using Facebook on perceptions of others' lives. Cyberpsychology, Behavior and Social Networking, 15, 117-121. https://doi.org/10.1089/cyber.2011.0324

Effendi, O.U. (1986). Dinamika Komunikasi. Bandung :CV Remaja Rosdakarya

Festinger, Leon (1954). A theory of social comparison processes. Human Relations. 7. 117140.

Feinstein, B. A., Hershenberg, R., Bhatia, V., Latack, J. A., Meuwly, N., \& Davila, J. (2013). Negative social comparison on Facebook and depressive symptoms: Rumination as a mechanism. Psychology of Popular Media Culture, 2, 161-170. https://doi.org/10.1031/a0033111.

Gibbons, F. X., \& Buunk, B. P. (1999). Individual differences in social comparison: Development of a scale of social comparison orientation. Journal of Personality and Social Psychology, 76, 129-142. http://dx.doi.org/10.1037/0022-3514.76.1.129.

Graber, D., (2014, October 8). 3 Reasons Why Social Media Age Restriction Matters. Huffingtonpost.com. Retrieved from https://www.huffingtonpost.com/.

Haferkamp, N., \& Kramer, N. C. (2011). Social comparison 2.0: Examining the effects of online profiles on social-networking sites. Cyberpsychology, Behavior and Social Networking, 14, 309-314. https://doi.org/10.1089/cyber.2010.0120.

Hurlock, E. B. (1990). Psikologi Perkembangan: Suatu Pendekatan Sepanjang Rentang Kehidupan. Alih Bahasa: Soedjarwo dan Iswidayanti. Jakarta: Erlangga 
Haryanto, A.T. (2018, March 12). 130 Juta Orang Indonesia Tercatat Aktif di Medsos. Detikinet. Retrieved from https://inet.detik.com/.

Jalonen, H. (2014). Social Media And Emotions In Organizational Knowledge Creation. ACSIS. Vol. 2. 1371-1379. https://doi.org/10.15439/2014F39.

Jalonen, H. (2014). Social Media: An Area For Venting Negative Motions. International conference on communications, media, technology, and design. Istanbul, Turkey. Finland: Turku University of Applied Sciences.

Kenapa Kita Sering Membandingkan Diri Dengan Orang Lain di Medsos?. (2018, June 17). Retrieved from https://lifestyle.kompas.com/. Diakses pada 06 Januari 2020

Kalpidou, M., Costin, D., \& Morris, J. (2011). The relationship between Facebook and the well-being of undergraduate college students. Cyberpsychology, Behavior, and Social Networking, 14, 183-189. https://doi.org/10.1089/cyber.2010.0061.

Kaplan, H.B. dan Stiles, B.L. 2004. Adverse social comparison processes and negative self-feelings: a test of alternative models. Social Behavior and Personality, 2004.

Krasnova, H., Wenninger, H., Widjaja, T., \& Buxmann, P. (2013, March 1). Envy on Facebook: A hidden threat to users' life satisfaction?. International Conference on Wirtschaftsinformatik, Leipzig, Germany. Darmstadt: Technische Universität.

Kross, E., Verduyn, P., Demiralp, E., Park, J., Seung-jae Lee, D., Lin, N,...Ybarra, O. (2013). Facebook use predicts declines in subjective well-being in young adults. PLoS One, 8, e69841. https://doi.org/10.1371/journal.pone.0069841.

Lim, M., \& Yang, Y. (2015). Effects of users' envy and shame on social comparison that occurs on social network sevices. Computers in Human Behavior, 51, 300-311. https://doi.org/10.1016/j.chb.201.05.013.

Lockwood, P., \& Kunda, Z. (1997). Superstars and me: Predicting the impact of role models on the self. Journal of Personality and Social Psychology, 73, 91-103. https://doi.org/10.1037/0022-3514.73.1.91.

Marsh, H. W., \& Parker, J. W. (1984). Determinants of student self-concept: Is it better to be a relatively large fish in a small pond even if you don't learn to swim as well?. Journal of Personality and Social Psychology, 47, 213-231. https://doi.org/10.1037/0022 3514.47.1.213.

Mehdizadeh, S. (2010). Self-presentation 2.0: Narcissism and self-esteem on Facebook. Cyberpsychology, Behavior, and Social Networking, 13, 357-364. https://doi.org/10.1089/cyber.2009.0257

Morse, S., \& Gergen, K. J. (1970). Social comparison, self-consistency, and the concept of self. Journal of Personality and Social Psychology, 16, 148-156. https://doi.org/10.1037/h0029862

Santrock, J. W. (2011). Life Span Development Perkembangan Masa Hidup. Edisi 13. Jakarta: PT Gelora Aksara Pratama.

Smith, J.W., \& Kim, S.H. (2007). Comprehending envy. Psychological Bulletin, 133, 46-64. https://doi.org/10.1037/0033-2909.133.1.46.

Park, S. Y., \& Baek, Y. M. (2018). Two faces of social comparison on Facebook: The interplay between social comparison orientation, emotions, and psychological wellbeing. Computers in Human Behavior, 79, 83-93. https://doi.org/10.1016/j.chb.2017.10.028.

Putra, 2017 Hubungan antara perbandingan sosial dengan teman sebaya dan meterialisme pada remaja. Skripsi tidak dipulikasikan. https://repository.usd.ac.id/12733/2/139114080_full.pdf diakses pada 15 Maret 2020

Taylor, Peplau, Sears. (2009). Psikologi Sosial. Depok : Prenadamedia Group. 
Pyszczynski, T., Greenberg, J., \& LaPrelle, J. (1985). Social comparison after success and failure: Biased search for information consistent with a self-serving conclusion. Journal of Experimental Social Psychology, 21, 195-211. https://doi.org/10.1016/0022-1031(85)90015-0.

Stapleton, P., Luiz, G., \& Chatwin, H. (2017). Generation validation: The role of social comparison in use of instagram among emerging adults. Cyberpsychology Behavior, and Social Networking, 20 (3). https://doi.org/10.1089/cyber.2016.0444.

Rutledge, C. M., Gillmor, K. L., \& Gillen, M. M. (2013). Does this profile picture make me look fat? Facebook and body image in college students. Psychology of Popular Media Culture, 2, 251-258. https://doi.org/10.1037/ppm0000011.

Vogel, E., Roberts, L., Rose, P.R. (2014). Social comparison, social media, and self-esteem. Psychology Of Popular Media Culture. Vol. 3, No. 4, 206-222. https://doi.org/10.1037/ppm0000047.

Vogel, E., Rose, J., Okdie, B., \& Eckles, K. (2015). Who compares and despairs? The effect of social comparison orientation on social media use and its outcomes.
Personality and
Individual
Differences,
86 ,
$249-256$ https://doi.org/10.1016/j.paid.2015.06.026.

de Vries, D.A., \& Kühne, R. (2015). Facebook and self-perception: Individual susceptibility to negative social comparison on Facebook. Personality and Individual Differences, 85, 217-221. https://doi.org/10.1016/j.paid.2015.05.029.

Weinstein, E. (2017). Adolescents' differential responses to social media browsing: Exploring causes and consequences for intervention. Computers in Human Behavior, 76, 396-405. https://doi.org/10.1016/j.chb.2017.07.038.

Wood, J.V. (1989). Theory and research concerning social comparisons of personal attributes. Psychological Bulletin. 106. No. 2. 231-248. https://doi.org/10.1037/00332909.106.2.231.

Yang, C-c., Holden, S.M., Carter, M.D.K., Webb, J.J., (2018). Social media social comparison and identity distress at the college transition: A dual-pathmodel. Journal of Adolescence 69. (2018) 92-102. doi: 10.1016/j.adolescence.2018.09.007.

Yang, C-c., \& Robinson, A. (2018). Not necessarily detrimental: Two social comparison orientations and their associations with social media use and college social adjustment. Computers in Human Behavior, 84, 49-57. https://doi.org/10.1016/j.chb.2018.02.020. 